\title{
Book Review: Colin Heywood's Childhood in Modern Europe
}

\author{
Reviewed by Sabiha Didar Tutan
}

Sabiha Didar Tutan is a research assistant and a graduate student in comparative studies in history and society at Koç University, Istanbul, Turkey. She recently completed her BA in international relations and philosophy. Her current research interests are sociology of crime and deviance and childhood studies. Email: stutan14@ku.edu.tr

Book Review: Childhood in Modern Europe

Author: Colin Heywood

Cambridge University Press, 2018, 280 pp

ISBN: 9780521685252

Childhood in Modern Europe (Cambridge University Press, 2018, 280 pp.) is a meaningful contribution by Colin Heywood to the textbook series "New Approaches to European History" The book clearly introduces and explores the major themes and problems in the history of childhood studies in Europe. The work brings together existing studies of childhood across Europe and adopts a comparative approach; its scope includes the Mediterranean regions, Russia, Western Europe, and the Nordic countries, although northwestern Europe is its primary focus. Heywood also considers the interaction with the United States, the imperial conquests, and mass migratory movements where relevant. The book's take on these issues does not aim to be comprehensive or partial; it mostly covers these issues practically and to the extent that they had repercussions for either children's lives or children's studies. However, I found it useful for contextualizing these changes in a wider context. For instance, Heywood acknowledges how the increased cultural influence of the United States in the $20^{\text {th }}$ century was welcomed in some ways and resented in others rather than making an overarching case for how the United States was perceived independent of context.

Contemporary childhood studies welcomes research from diverse disciplines, and research of the history of childhood has a foundationally informative role for the field as a whole. History of childhood is essential because it "defamiliarizes the present and helps us understand the distinctiveness of contemporary society's value system and social arrangements" (Mintz, 2012, p. 17). This process of defamiliarization is useful to question what we have taken for granted as being a natural part of childhood and invites us to adopt a critical approach to existing concepts in our respective disciplines regarding childhood, such as psychology or criminology. Therefore, this detailed curation of the history of childhood is a resource to be welcomed by scholars who are not historians but are interested in studying childhood. Heywood engages with past and current historical contentions in the field, engaging critically with what he calls "a tendency among historians of childhood to adopt a 'Whiggish' approach to their subject" (p. 10). Taking issue with the all too common description of an inevitable-sounding evolution to our modern, middle-class, privileged, or protected childhood, Heywood underlines the diverse experiences children and adolescents have had by bringing attention to the historical evidence against the notion of a protective childhood. This raises the question of innocence in childhood and adolescence, making the reader question whether it is possible or even desirable for children to maintain a distance from so-called threats to innocence. Heywood notes that there is already "a reluctant acceptance that children cannot remain 'innocent' in a highly sexualised society" (p. 10). If we consider this arguably uncomfortable reality, we are invited to think more critically as adults in contemporary societies about the measures we take in the name of protecting children. In contentious debates involving children we may encounter in life, the arguments in favour of protecting children may feel unobjectionable or very difficult to defeat. The belief that we must protect our children at all costs owes its status of common currency to the unfortunate reality that children are often vulnerable in their relationship 
to adults. However, "protecting children" as a general aim is a nebulous one, and we may need to think harder about what it is about children that we are trying to protect. Considering that the relationship between innocence and childhood is an important ongoing debate in childhood studies, reading about the historical changes in this relationship is important. The particular significance of this relationship will be discussed further in this review.

\section{How the book is organized}

The book consists of an introduction that outlines different theoretical approaches to the study of childhood, followed by three parts focusing on studies of Europe from the early $18^{\text {th }}$ century to the turn of the $21^{\text {st }}$ century. The introductory chapter is extremely useful in contextualizing the detailed work that follows it. In it Heywood provides an engaging account of the studies of childhood in the social sciences, beginning with the division of academic labour in the late $19^{\text {th }}$ century that assigned the child to the field of psychology, the family to sociology, the tribe to anthropology, and the school to education. Heywood explains that in this model, the study of childhood was mainly under psychology's developmental paradigm and was largely ignored by other social sciences. While the study of childhood has come to concern other disciplines in the social sciences, the developmental paradigm is by no means inconspicuous in contemporary societies. Understanding childhood as consisting of a given set of developmental phases is still a common frame of reference in everyday conversations about childhood.

Heywood locates the changes in the childhood studies field in the 1960s and 1970s, citing the role of the intellectual climate in questioning established values in rethinking the study of childhood. He points out a marked shift in the new approach: the acknowledgment of cross-cultural variation in both childrearing practices and the expected level of skill from children. A shift no less important that is also explored in the book was the adoption of a child-centered approach with an emphasis on children's autonomy. Although centering children's autonomy in our analysis of childhood may sound commonsensical, children often find themselves in marginalized positions in life. Our legal systems often put parents' decisions above children's autonomy; in fact, not constraining some of their children's decisions out of respect for the child's autonomy may have serious consequences for parents. Norvin Richards (2010) correctly points out that if parents were to treat their children as adults treat each other in terms of liberties, they would likely lose custody of their children. It seems that in our society, we require parents to exert authority over their children when we see fit. Usually, parents also want to exert authority over their children; however, parental control can seriously threaten children's autonomy-related interests, and we cannot always assume parents are making decisions that are in the best interest of their children. The reasoning behind constraining children's decision-making power is often their lack of capacity for rational judgment. It's likely that complete lack of constraint may result in some bad decisions; however, it is misleading to think of decisions in terms of being either good or bad and assigning parents to the former category and children to the latter. Children are not categorically failed decision makers and parents are not categorically successful decision makers. Martyn Hammersley (2017) notes the complexity of agency and the danger of treating it dichotomously and misleadingly as "simply opposing a passive model of children" (p. 119); he calls for "a sophisticated middle position" (p. 119). We may instead consider children's agency as something that can be cultivated; in fact, interest in understanding children's agency "invites interdisciplinary collaboration in research on the practical implications of children's agency" (Sorbring \& Kucynski, 2018, p. 4). The role of family and school in this process of cultivation would be good candidates for exploration. Sirkko et al. (2019) underline the role of early childhood education settings for the realization of children's agentic rights. Parents' role can be enabling for children to gain a sense of agency, and it can be constraining. Vandenbroeck and Bouverne-De Bie (2006) argue that the construction of the "fragile child" in the $19^{\text {th }}$ century was closely related to industrialization, urbanization, poverty, child mortality, and the abolition of child labour; this construction also interconnected with the construction of the "responsible mother" with duties to fulfil towards both the child and society. Given that the social context has changed remarkably since 
the $19^{\text {th }}$ century, how can we challenge the notion of the fragile child in need of protection in our research? In one of the recent contributions to the debate on children's agency in childhood studies, Kontovourki and Theodorou (2019) use the notion of performativity to "unravel immigrant children's narrations and identity performances" (p. 153), underlining the fact that the interview process with children is itself a performative space. Their observance raises the question of plausibility of the child as agent and raises questions about the methodological implications of interviewing children during research.

Taken together, the questioning of established values and the acknowledgment of cross-cultural variation in childrearing practices can be interpreted as a reaction against the developmental paradigm. Compelling challenges to this paradigm have further political implications. For instance, Moran-Ellis and Sünker (2018) assert that the developmentalist position limits our imagination of children as participants in political life, with the result that we delay "participation for children until they have reached some hard-to-specify level of cognitive ability" (p. 289).

Taking into account the vast differences in definitions and experiences of childhood despite all children "having the same biological starting point" (Heywood, p. 5), some historians, as well as social scientists, have considered childhood to be a social construction. Heywood acknowledges the merits of the social constructivist approach but correctly points out that it "leaves open awkward questions on the relationship between the biological and the social" (p. 6). He cites Alan Prout who warns against downplaying the biological and material dimensions, which risks ignoring the bodies of children-an invaluable source of evidence for a research study. Two universal challenges persisting in the study of the history of children are the scarcity of archival material about and by children despite children making up a significant percentage of society. Given the scarcity of sources written by children, historians often have to rely on sources written by adults. This creates a thought-provoking dilemma for the reader. Given that many accounts of childhood (particularly early childhood) are documented by adults, can these historical works be considered more a literary form with the inescapable creative role of the author in its reconstruction? Heywood does not give a definitive answer to this question but aims to reconstruct the conceptions of childhood both as a lived experience and as a concept in the minds of adults. Regardless of the validity of archival resources, Heywood points to a preliminary challenge: accepting that childhood is a subject worth studying in its own right. Today, childhood with its many complexities has come to be an important subject of study for many fields in social science.

The first point that persists throughout Childhood in Modern Europe is the definition of childhood. Of course, the age boundaries of childhood differ across time and space. In the absence of a criterion to determine these boundaries, defining childhood becomes difficult. Much contention about boundaries of childhood exists in the literature, some of which I discuss in this review. Looking at some biological markers, Thompson and Nelson (2016) argue that childhood "begins at about age three when human offspring can begin to provision some of their daily energy requirements themselves" (p. 82), and in some studies, the beginning of childhood is tied to weaning, following infancy. This discrepancy is something I find difficult in my assessment of academic research about children, because childhood can refer to such a long time period in a person's life. This discrepancy also suggests that researchers can select and justify a criterion for childhood that is tailored to the purpose of their research, which makes it difficult to use the term comparatively and widely. Determining when childhood begins and ends biologically becomes an impossible-to-answer question, yet it is a matter of historical research to discover which criteria ordinary people used to make this distinction irrespective of its consistence with biological factors. Childhood in Modern Europe takes on this task. Heywood notes that in preindustrial Europe, the skill and strength of the individual determined the status rather than an age category. Another factor could be the extent of dependence on other adults. Thus, Childhood in Modern Europe does not adopt strict age parameters. Instead, the United Nations definition of a child as anyone under 18 years of age is used as "a rough guide" (p. 13). 
The scope of the book covers the period from the early $18^{\text {th }}$ century to the turn of the $21^{\text {st }}$ century. The theoretical discussion explained so far takes place in the introduction, while the historical discussion is divided into three parts. These parts are organized chronologically and according to their location, namely urban and rural. Part I: Childhood in Villages, Eighteenth and Nineteenth Centuries is concerned with conceptions of childhood in rural society. Part II: Childhood in Towns (c.1700-1870) focuses on the impact of developments such as the Enlightenment and Romanticism, as well as the Industrial Revolution, on children. Part III: Childhood in an Industrial and Urban Society discusses the period beginning around 1870 and deals mainly with childhood in an affluent society that aspires to protect the young from some aspects of adult life.

The books main points of discussion selected for the purposes of this review can be organized around the following three themes: the changing definitions and significance of childhood across time and space; the changing relationship between religion, education, and work for children; and children and agency. In the discussion that follows, each theme is inevitably present in the analysis of the others; for instance, the reader will see that religion influenced the definition(s) of childhood, which in turn had implications for children's agency.

\section{The changing definitions and significance of childhood}

Heywood explains that what marked the end of the early phase of childhood in the villages of Europe during the $18^{\text {th }}$ and $19^{\text {th }}$ centuries was the young's development of abilities to help around the home, the farm, and the workshop; parents gradually increased the difficulty of the tasks as children gained strength. Although the criterion was skill development, it differs from the traditional developmentalist paradigm since these boundaries were determined by individual circumstances rather than rigid and predetermined developmental stages. Heywood demonstrates a considerable variation in the type of work expected from children and practices of moving away from home, which suggests that neither puberty nor a fixed age were of decisive importance in determining these boundaries. The final step towards adulthood in rural Europe was marriage; however, Heywood also demonstrates the considerable variation in age boundaries across countries. Couples in England and the Nordic countries married late, towards the end of their twenties, whereas earlier marriage was common in eastern and southern Europe. What marked the difference between rural and urban boundaries was higher school attendance in towns. The age-grading of school systems had increasingly stronger influence in marking the beginning and end of childhood in towns beginning from the middle of the $18^{\text {th }}$ century. During the $19^{\text {th }}$ century, formal education became increasingly important, making the end of elementary school a discernible boundary to mark the end of childhood. The amount of evidence this book contains to demonstrate the diversity of definitions across Europe is too great to be covered in this review; what is discussed above is a fraction of the evidence provided by Heywood, which show that the boundaries of childhood were and continue to be elusive.

Heywood also carefully explores the changes in the meaning of childhood, in addition to the variation in milestones drawing the boundaries of childhood, such as education ending and marriage. The meaning of childhood also experienced a shift from a more religiously inspired notion inherited from the medieval period to a more secular perspective which can be traced to the intellectual contributions of the Enlightenment. A significant part of the first chapter is devoted to the influence of the Enlightenment and Romanticism and their role in encouraging people to take childhood more seriously. The Enlightenment's lasting influence was the emergence of a more secular perspective on the notion of childhood. John Locke's definition of the boundary between childhood and adulthood was the capacity to exercise judgment. Locke's emphasis on the capacity to exercise judgment is still relevant for childhood rights to this day since it underlines the limitedness of childhood's capacity. In other words, children by definition lack the capacity to exercise judgment. Another influential intellectual discussed in this chapter is Jean-Jacques Rousseau, who argued that children had a particular way of seeing, thinking, and feeling. 
Rousseau's book Emile was highly influential in terms of the perception of children's education. Heywood notes that Rousseau's interest in feelings often makes him appear as a transitionary figure between the Enlightenment and the Romantic era. Heywood provides ample evidence to show the Rousseauist and Romantic influences on poets, novelists, and painters including Delacroix and Goya. The chapter also includes notable paintings, including Childhood by Joshua Reynolds and Otto Sigismund, der Sohn des Künstlers by Otto Runge as illustrative figures. Heywood concludes that the popularization of such Romantic depictions of the pure and innocent child fuelled the emergence of the modern "protected" childhood that can also be associated with the welfare state. As discussed earlier in this review, depicting children as lacking judgment and being innocent figures in need of protection has had serious ramifications for what we expect from and offer to children. Bringing this tension to the present has led me to think deeply about how we define childhood today. In contemporary research, to what extent are we aware of the Enlightenment's and Romanticism's impact when we are theorizing childhood?

\section{Religion, education, and work}

Religion, education, and work are three concepts that are closely related to each other, not only in this book, but in children's lived realities as well. In the absence of the notion of a protected childhood according to which children should not be working but rather should focus on playtime or education, children were routinely called on to help with various tasks, including working on the land. I gathered from this book that attitudes towards children working were not negative in early modern Europe; children did not have a privileged position in the household which would free them from the burdens of work. Education's relationship with religion was also much more straightforward; in rural society, teaching usually took place in churches, a priest's house, a cottage, or a barn. Heywood explains that children were important targets in the efforts of the Church to assert influence in everyday life since many of the early schools were founded as philanthropic work, attempting to teach the basics of Christian doctrine and morality. Persuading the peasantry to send their children to school was a cause for conflict because of the extended amount of time the school kept children away from work. Urban children, although they may not have been working on the land, were a part of the labour force working in factories, and securing a job for a child was crucial for working-class parents. Heywood further details the motives and constraints of the parents in expecting work from children beyond what I have exemplified above. I believe thinking about the motives and constraints of the parents at that time and recognizing that the notion of a protected childhood was not prevalent is important today because of the sharpness of the contrast we can observe in two parenting approaches. Simply put, there is a strict stance today against children working instead of going to school, and working under the age of 18 is heavily regulated in Europe. The prevalence of this opinion is overwhelming to the point that it becomes easy to miscalculate the early modern European parents' rationale and make anachronistic judgments about it if we are not informed about the content of the education in that time as well as the social context in which these parents put their children to work.

Heywood's chronological exploration of the relationship between religion, work, and education reveals that the increased tension between these three forces in Europe seems to have resulted more or less in favour of a more secularized education with a resistance to child labour-although this change occurred rather slowly. In fact, Heywood explains that the children of early modern rural Europe grew up with the expectation of marrying and starting a family of their own, thus they had to be concerned with earning a good reputation as a worker and a dutiful Christian as well as saving money for this future. Compared to the new industrial centres of the $19^{\text {th }}$ century, growing up in villages spared children from schools, reformatories, and barracks. On the other hand, agricultural societies expected hard work from children in farms and workshops. In general, urban and rural children were faced with different expectations and challenges. Although there was a general trend towards mass schooling in the $19^{\text {th }}$ century, the urban environment had more suitable conditions than the rural one to embrace this shift towards 
schooling. So, the scale of change that would be required to result in a long-term decline in the employment of children needed intervention from an external actor such as the state, which would not materialize until the middle of the $19^{\text {th }}$ century. Even when we discuss mass schooling, we cannot make sweeping generalizations about all children in Europe; class and gender become an important variable to consider. For instance, Heywood argues that middle-class family life is set apart by the family's willingness to spend money on literature for their children. The middle classes were committed to educating their children, even though the meaning of education differed for boys and girls. The belief that girls were best educated in the household and by their mothers is shown in the book to have been prevalent in early modern Europe; however, parents sending their daughters to school was practiced more widely throughout the $19^{\text {th }}$ century. School gaining more decisive primacy over work on the list of priorities did not happen until the late $19^{\text {th }}$ and $20^{\text {th }}$ centuries.

Although education is considered a right, religion as an institution is much more narrowly involved in education, and children's labour is regulated in Europe, the tensions between them sometimes resurface in contemporary debates regarding children. Keeping in mind Heywood's point that it required external involvement from a powerful actor such as the state to create a decisive turn in favour of mass schooling and against the employment of children, how should we think about the role of the state today in addressing the tensions and inequalities that persist? What role should it play, if any?

\section{Children and agency}

A notable issue Heywood deals with is the "death of childhood" thesis. According to this thesis, the appearance of the idea of childhood is related to the spread of literacy because it made it possible for adults to "control the symbolic environment of the young" by being able to keep secrets from children in written form (p. 187). With further development of technology, the innocence of a child was disappearing in modern society with children being more aware of adult life due to television being readily accessible. Essentially, according to this thesis, by children once again joining the adult world, the boundaries between childhood and adulthood became further blurred. Heywood explains this position and accepts that the digital revolution made adult material available; however, he heavily criticizes some of the assumptions of this thesis. Of course, this thesis makes no reference to class and gender distinctions and "proposes a determining influence on human behavior of technology" and "ignoring the social context" (p. 188). However, Heywood's most significant criticism against this thesis is its lack of attempt "to discover what children themselves think" (p. 188). I think this criticism is worth highlighting because it gives voice to a muted and vulnerable minority; it suggests that children are beings whose opinions are not considered in cases where they should be. I also think that abandoning the death of childhood thesis can invite people to call for further exposure of young people to realities they will eventually grow into instead of calling for a restoration of children's supposed innocence. Heywood does not deny the digital revolution's impact on children's exposure to the so-called adult world, though-he accepts technology's role in "undermining the construction of child as an original innocent" (p. 188). The view he considers more plausible is that technology has "increased the distance between the generations, as children embraced the new forms of communication with far more enthusiasm than adults" (p.188). In this sense, his interpretation is that children have merely become more informed without necessarily making a claim about the desirability of this change. The knowing child or the competent child "is surely taking over from the supposedly innocent one" he concludes (p. 189).

Heywood further underscores the importance of an affluent society having more parents with more disposable income, which made children consumers in the market. This newly recognized competence is in stark contrast to the earlier position of children in which they were "in effect considered to be the property of their parents"-their fathers in particular (Heywood, p. 191). As a vulnerable minority, children need protective rights but also, as some 
argue, participatory rights. This bold perspective challenges the all-too-common assumption about the limited capacity of children that is pervasive in contemporary discourse about childhood. The emergence of children as rights holders also implicitly challenges the conception of children as becomings rather than beings, highlighting their autonomy. Heywood locates the signs of this change as happening around the turn of the $21^{\text {st }}$ century, during which children's rights movements argued for the need to give children "a greater say in the running of their own lives" (p. 194). Grand theories which are in search of universal laws that are relevant for children across time and space become questionable in the face of historical evidence of diversity demonstrated throughout this book. Recognizing the vulnerable position of children, how can the tension between protecting children and recognizing their autonomy be resolved? In what ways can we advocate for an approach to childhood that is more sensitive towards children's empowerment?

Overall, Childhood in Modern Europe provides a detailed and multidimensional reconstruction of childhood in each particular historical period, outlining the continuities as well as major shifts across time and region excellently. Considering the wideness of Europe, each issue Heywood analyzes has considerable regional variation; he is successful in taking into account this variation and avoids sweeping generalizations. Heywood's work also goes beyond a survey of the main theoretical approaches and corresponding empirical evidence; he also discusses the moral implications of the findings of these studies. A demonstrative example is scholars questioning "the legitimacy of the existing distribution of power and authority between adults and children" and whether adults always acted "in the best interests of the child" (p. 7). As shown throughout this review, Heywood tries to make the reader doubt the notion of a protected childhood and really underscores the fact that children have voices of their own that need to be taken seriously. This concern is taken up in Part III with the legal recognition of children as rights holders. I found the legitimacy discussion to be thought-provoking because it consistently challenges a deep assumption commonly held in contemporary society about children's legal position with respect to adults. Despite observing how children's rights can be routinely violated under the pretence of looking out for their best interests, I also understand how such violations can be written off as the parents' discretion. When we think critically about the common discourses about children and childhood, the enormous influence parents have over their children's lives is assumed to be justified in most cases, unless there is a legal demonstration of abuse or neglect. What are the boundaries of abuse and neglect is really an open question, and the answers given to it change across cultures and centuries. The readily accepted and rarely questioned status of parents as disproportionately powerful influences over their children's lives ultimately creates the impression of an unresolvable ethical dispute between children and parents, albeit a temporary one until the child grows into an adult. Heywood is careful in handling the precarious position of children with respect to their relationships with adults, thus he is able to introduce more critical arguments without marginalizing them. Since each part of the book can operate as a stand-alone piece, I felt like I could recommend any chapter individually as a solid introduction to researchers new to the field with confidence. In the case of my research interest, which mainly concerns the ethics of parenthood and autonomy of children, the discussion in the book regarding children's agency and status as rights holders would become a key recommended resource to provide historical context. Historically, what were the filial obligations children had towards their parents? Which external influences and internal motivations changed the obligations parents had towards their children? How did parents perceive their children and how did children perceive themselves? Were children always perceived to be innocent? Answers to these questions can be found in this book and can inform researchers and practitioners. I should also note that despite acknowledging the very material impact children had in the society by being workers and consumers, Heywood does not hold a naïve position in terms of the negotiating power children had. In the conclusion, he recognizes that children's negotiations with adults were and continue to be from a position of weakness.

A notable strength of this book is its accessible adjudication of scholarly debates on the study of childhood. 
Heywood not only presents these debates but often gives a balanced account of the strengths and weaknesses of each position, which makes it easier for readers who are foreign to the study of childhood by taking up the challenge to connect histories of childhood to broader social, political, and economic changes in the society. Childhood in Modern Europe has much to offer that cannot possibly be covered in a review. It introduces the reader to key debates in childhood studies, such as children's role as workers as well as consumers, the role of religion and religious institutions in children's lives, gender as a cross-cutting influence in childhood, schooling practices, and children's status as a minority group in European society. The book's contribution to these debates is not in the form of providing new empirical evidence; rather, its strength is in presenting and contextualizing existing research for its audience. I am confident that a careful reader will find the book rewarding regardless of their previous familiarity with the field. 


\section{References}

Butterfield, H. (1931), The Whig interpretation of history. G. Bell \& Sons.

Hammersley, M. (2017). Childhood studies: A sustainable paradigm? Childhood, 24(1), 113-127. https://doi. org/10.1177/0907568216631399

Heywood, C. (2018). Childhood in modern Europe. Cambridge University Press.

Kontovourki, S., \& Theodorou, E. (2019). Performative politics and the interview: Unraveling immigrant children's narrations and identity performance. In S. Spyrou, R. Rosen, \& D. T. Cook (Eds.), Reimagining childhood studies. Bloomsbury Academic.

Mintz, S. (2012). Why the history of childhood matters. The Journal of the History of Childhood and Youth, 5(1), 15-28. https://doi. org/10.1353/hcy.2012.0012

Moran-Ellis, J., \& Sünker, H. (2018). Childhood studies, children's politics and participation: Perspectives for processes of democratisation. International Review of Sociology, 28(2), 277-297. https://doi.org/10.1080/03906701.2018.1477106

Richards, N. (2010). The ethics of parenthood. Oxford University Press.

Sirkko, R., Kyrönlampi, T., \& Puroila, A. (2019). Children's agency: Opportunities and constraints. International Journal of Early Childhood, 51(3), 283-300. https://doi.org/10.1007/s13158-019-00252-5

Sorbring, E., \& Kucynski, L. (2018) Children's agency in the family, in school and in society: Implications for health and well-being, International Journal of Qualitative Studies on Health and Well-Being, 13(sup1). https://doi.org/10.1080/17482631.2019.1634414

Thompson, J. L., \& Nelson, A. J. (2016). Childhood and patterns of growth in the genus homo. In C. L. Meehan \& A. N. Crittenden (Eds.), Childhood: Origins, evolution, and implications. University of New Mexico Press.

Vandenbroeck, M., \& Bouverne-De Bie, M. (2006). Children's agency and educational norms: A tensed negotiation. Childhood, 13(1), 127-143. https://doi.org/10.11770907568206059977 